REGARDS

SUR L'ECONOMIE ALLEMAND

BULLETIN ECONOMIQUE DU CIRAC
Regards sur l'économie allemande

Bulletin économique du CIRAC

$92 \mid 2009$

Varia

\title{
Fisc : la part des impôts « écologiques » en baisse
}

Isabelle Bourgeois

\section{OpenEdition}

Journals

Édition électronique

URL : http://journals.openedition.org/rea/3766

DOI : $10.4000 /$ rea.3766

ISBN : 978-2-8218-0880-5

ISSN : 1965-0787

Éditeur

CIRAC

Édition imprimée

Date de publication : 1 juillet 2009

Pagination : 35

ISSN : 1156-8992

Référence électronique

Isabelle Bourgeois, "Fisc : la part des impôts « écologiques » en baisse », Regards sur l'économie allemande [En ligne], 92 | juillet 2009, mis en ligne le 01 juillet 2011, consulté le 15 septembre 2020. URL : http://journals.openedition.org/rea/3766

Ce document a été généré automatiquement le 15 septembre 2020.

(C) CIRAC 


\title{
Fisc : la part des impôts « écologiques » en baisse
}

\author{
Isabelle Bourgeois
}

1 Alors que le total de l'encours fiscal a progressé de $26,9 \%$ entre 2003 et 2008, les recettes des impôts « écologiques » ont, elles, reculé de $4,7 \%$. Leur part dans le total est tombé de $12,9 \%$ en 2003 à 9,7 \% cinq ans plus tard, soit le même niveau qu'avant l'entrée en vigueur de la Loi sur la réforme écologique de la fiscalité (Gesetz zum Einstieg in die ökologische Steuerreform) le $1^{\mathrm{er}}$ avril 1999.

2 Ce recul est principalement le fait d'une taxe parmi les trois qui relèvent de la catégorie statistique internationale des impôts " écologiques » : la taxe sur l'énergie $(-9,1 \%)$. Car si l'encours de la taxe sur l'électricité a lui aussi baissé $(-4,1 \%)$, celui de la taxe sur les véhicules a au contraire augmenté de $20,5 \%$. Ce recul s'explique essentiellement par une modification intervenue dans la structure des ventes de carburants, explique Destatis: le diesel (taxé de 47,04 cents/litre) supplante aujourd'hui l'essence $(65,45$ cents/litre de sans plomb). Alors que le volume de diesel vendu en 2003 s'élevait à 33,1 millions de $\mathrm{m}^{3}$ (essence : 34,9 millions de $\mathrm{m}^{3}$ ), il est monté à 36,0 millions de $\mathrm{m}^{3}$ tandis que celui de l'essence tombait à 27,8 millions. A cela s'ajoute une légère diminution $(-2,3 \%)$ du volume de carburant vendu. Celle-ci a des origines complexes, où le changement dans le comportement de mobilité des Allemands ou l'évolution du parc automobile n'interviennent, semble-t-il, que très peu. Plus significatif est en effet l'apport du « tourisme de l'approvisionnement en carburants » dans une Allemagne aux neuf frontières, où les consommateurs ont l'habitude de comparer les prix (et les taxes) et de s'approvisionner à la station-service la moins chère. (IB)

Part des impôts « écologiques » dans l'encours fiscal et évolution 1998-2008

\begin{tabular}{|l|l|l|l|l|l|l|}
\hline & Total impôts & ...dont écologiques & part & \multicolumn{3}{|c|}{ Encours des trois types de taxes } \\
\hline & & & & Energie & Véhicules & Electricité \\
\hline
\end{tabular}




\begin{tabular}{|l|l|l|l|l|l|l|}
\hline & (millions $€)$ & $($ millions $€)$ & $(\%)$ & (millions $€)$ & (millions $€$ ) & (millions $€$ ) \\
\hline 1998 & 425838 & 41848 & 9,8 & 34091 & 7757 & - \\
\hline 1999 & 452998 & 45298 & 10,0 & 36444 & 7039 & 1816 \\
\hline 2000 & 467177 & 48197 & 10,3 & 37826 & 7015 & 3356 \\
\hline 2001 & 446170 & 53389 & 12,0 & 40690 & 8376 & 4322 \\
\hline 2002 & 441628 & 54882 & 12,4 & 42193 & 7592 & 5097 \\
\hline 2003 & 442167 & 57055 & 12,9 & 43188 & 7336 & 6531 \\
\hline 2004 & 442761 & 56118 & 12,7 & 41782 & 7739 & 6597 \\
\hline 2005 & 452079 & 55236 & 12,2 & 40101 & 8673 & 6462 \\
\hline 2006 & 488444 & 55126 & 11,3 & 39916 & 8937 & 6273 \\
\hline 2007 & 538243 & 54207 & 10,1 & 38955 & 8898 & 6355 \\
\hline 2008 & 561182 & 54350 & 9,7 & 39248 & 8842 & 6261 \\
\hline
\end{tabular}

Source des données : Destatis, Pressemeldung n² 244 (01-07-2009). NB : Total impôts après déduction des prestations de transfert social. Taxe sur l'énergie : carburants seuls jusqu'en 2006. Chiffres arrondis.

\section{INDEX}

Mots-clés : impôts, fiscalité, politique fiscale, taxe, protection de l'environnement, écologie 